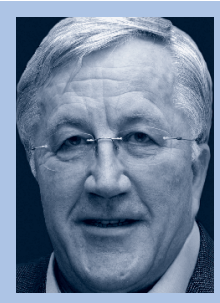

Prof. Dr. rer. nat. med. habil. Rainer Breul D.O. h.c.
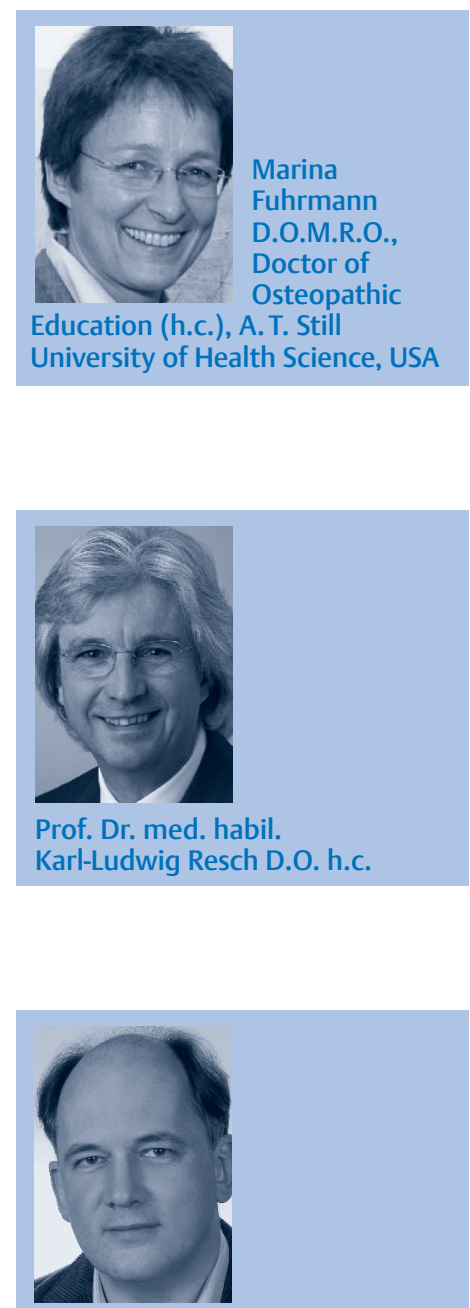

Dr. med. Roger Seider D.O.

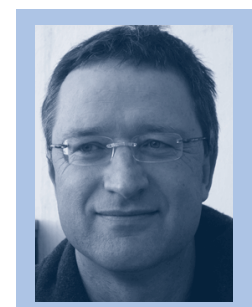

Peter Wührl D.O.

\title{
Palpation, ein Skandal?
}

$\mathrm{F}$ ür viele Nicht-Osteopathen und selbst für uns Osteopathen ist Palpation ein Skandal, ein Stein des Anstoßes. Das Thema Palpation ist ein Trigger, was an die wörtliche Bedeutung von skandalon im Griechischen erinnert, jenes kleine Stück Holz, das bei Berührung die Falle zuschnappen lässt. Wer könnte ein deutlicheres Bild ersinnen: bei Berührung schnappt die Falle zu.

Einzig, wir sitzen gern in dieser Falle. Kommt das Gespräch unter Osteopathen auf Palpation, bringt es selbst schweigsame Geister zum Reden, werden selbst pragmatische Gemüter visionär und selten fehlt der glühende Blick des stolzen Handwerkers und der ergriffene Ton des Propheten. Etwas wird angestoßen, im Handumdrehen kreist die Diskussion um lebensphilosophische Themen und zuweilen geraten die Heilungsansprüche derart aus der Hand, dass sie universelle Reichweite beanspruchen. Das Thema Palpation offenbart dann schnell, dass selbst in grundlegenden Fragen kreative Uneinigkeit herrscht: palpieren wir mit der Hand, den Sinnen, unserem ganzen Sein? Was ist eigentlich das Medium der Palpation, ihre Sprache? Können wir Vergangenes ebenso palpieren wie Gegenwärtiges?

Was Palpation aber so skandalös erscheinen lässt, ist die Leichtigkeit, mit der sie sich über unvereinbare Gegensätze hinwegsetzt. Es ist ein Leichtes, eine Litanei an Widersprüchlichem über sie anzustimmen: Palpation ist subjektiv und objektiv, ist aktiv und passiv, neutral und verändernd, diagnostisch und therapeutisch zugleich. Einerseits ist Palpation für uns die Möglichkeit, objektive Zustände der Patienten zu erfassen, so objektiv, dass wir damit zuweilen genauer ausmachen können, wo der Heilungsprozess ansetzen kann, als eine bildgebende Maschine.

Andererseits ist Palpation unwiderruflich subjektiv, rührt an das Menschsein, denn in ihr stellen wir eine Beziehung zu uns und zu einem anderen her. Palpation ist Berührung, eine Begegnung, in der beide berührt werden und in der Osteopath und Patient verändert werden. Damit wäre die klinische Wahrheit, die sich in dieser Situation zeigen kann, ganz und gar in der Begegnung zweier Menschen begründet. Sie würde jeden Versuch, Interrater Reliabilität herstellen zu wollen sofort als behandlerzentrierte Reduktion diskreditieren. Auch die Neutralität des Therapeuten als Voraussetzung der Palpation hätte damit den Status der höheren Weihen verloren, denn wer neutral sein will, muss zudem erweisen, dass er oder sie auch zugewandt und im gemeinsamen Moment der Begegnung ist.

In all den gebundenen Widersprüchen ist es schon ein Ruhepol sagen zu können, was Palpation nicht ist: sie ist kein Perspektivwechsel und sie ist keine Auflösung der Subjekt-Objekt-Spannung. Aber gerade die Erfahrung der Palpation lässt Osteopathen manchmal vergessen, dass der Perspektivwechsel als therapeutische Anstrengung immer nötig und notwendig unvollständig, die Auflösung der Spannung dagegen unmöglich ist. Diese Illusion gehört zur Kraft der Palpation: Wir vergessen, dass andere eben nicht das Gleiche fühlen wie wir selbst. Bei aller Liebe, die biologischen Grundlagen der Einfühlung werden genauso gerne überschätzt wie dereinst die der Aggression. Zum Skandal der Palpation gehört, dass sie immer dann ungenau wird und ins Floskelhafte sich verliert, wenn ihr sozialer Kern und der konkrete Moment der Entstehung abgestoßen werden. Palpation ist nur möglich in der Begegnung zweier Subjekte, darin liegt ihre objektive Gültigkeit, und vielleicht auch ihre Chance, alle Versuche der Erforschung zu überstehen.

Die Herausgeber

Titelbild: PhotoDisc, Inc., Bearbeitung Pdesign, Stuttgart 2008. 